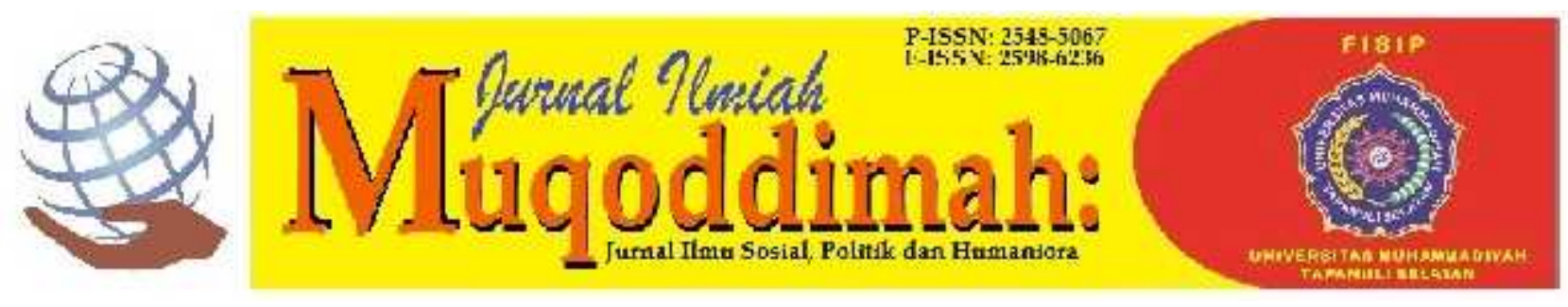

\title{
Analisis Penyebab Pelarian Narapidana di Rutan Kelas II B Sungai Penuh
}

\author{
Idham Imam Seputra, ${ }^{1)}$ Padmono Wibowo ${ }^{2)}$ \\ Manajemen Pemasyarakatan, Politeknik IImu Pemasyarakatan \\ Jl. Raya Gandul No.4, RW.6, Gandul, Kec. Cinere, Kota Depok, Jawa Barat 16514 \\ Idhamimams@gmail.com ${ }^{1)}$ \\ padmonowibowo@yahoo.co.id ${ }^{2)}$
}

\begin{abstract}
Abstrak
Penelitian ini mengambil lokus pada Rutan klas II B Sungai Penuh dengan focus masalah pelarian narapidana. Pelarian narapidana merupakan salah satu gangguan Kemanan dan Ketertiban yang terjadi pada lingkungan Lapas dan Rutan. Kasus pelarian narapidana menyebabkan pembinaan pada narapidana tersebut tidak berlangsung sehingga pencapaian tujuan pemasyarakatan menjadi terganggu, selain itu masyarakat merasa terancam dengan keberadaan narapidana tersebut dilingkungan mereka, sehingga penyebab narapidana melarikan diri menjadi hal yang sangat penting untuk dipelajari. Penelitian ini menggunakan metode penelitian kualitatif dengan desain deskriptif terhadap data yang didapatkan dari wawancara dan studi kasus, data diolah dan disajikan dengan diagram Fishbone. Penelitian ini menyimpulkan harus dilakukan perbaikan metode pengaman, peningkatan sarana pengamanan seperti CCTV, peningkatan kompetensi Petugas dan perbaikan tembok keliling sesuai standar pola bangunan pemasyarakatan.
\end{abstract}

Kata kunci : pelarian narapidana, pengamanan upt, pemasyarakatan

\begin{abstract}
This research took a locus at Rutan Class II B Sungai Penuh with a focus on the problem of prisoner escape. Escaping prisoners is one of the disturbances of security and order that occurs in prisons and detention centers. The case of escaping prisoners causes the prisoner's guidance to not take place so that the achievement of correctional objectives is disturbed, besides that the community feels threatened by the existence of these prisoners in their environment, so the cause of the prisoners running away is very important to be studied. This research uses qualitative research methods with descriptive design of the data obtained from interviews and case studies, the data is processed and presented with a Fishbone diagram. This research concludes that there must be improvements in security methods, improvement of security facilities such as CCTV, increasing competence of officers and repairing the surrounding walls according to the standard of correctional building patterns.
\end{abstract}

Keywords: escaped prisoners, security upt, correctional

\section{PENDAHULUAN}

Lembaga pemasyarakatan atau penjara merupakan lembaga yang berfungsi melakukan pembinaan terhadap orang-orang yang melakukan peanggaran hukum sebelum merek dikembalikan kepada masyarakat.

Sebagai dasar hukum pelasksanaan pidana penjara di Indonesia adalah Undang-Undang Nomor 12 Tahun 1995 tentang Pemasayarakatan(UU Pemasyarakatan)sebagai dasar hukum. Sejak saat itu pula pelaksaan pidana penjara Indonesia berubah pandangan dari pandagan penghukuman menjadi pendangan yang lebih manusiawi yaitu konsep pembinaan. Perubahan paradima ini sejalan dengan politik hukum Indonesia khusunya pemidanaan mulai bergerak kearah pembinaan. Gagasan yang dikemukaan oleh Dr. Sahardjo menyatakan bahwa 
pembinaan itu diperlukan untuk memberikan bekal bagi para pelaku kejahatan agar siap kembali beraktivitas dalam masyarakat.Muladi menegaskan bahwa sistem pemasyarakatan dibangun untuk mempersiapkan mental dan ketrampilan kepada narapidana agar kemudian dapat kembali memasyarakat.

Lembaga pemasyarakatan yang difungsikan sebagai tempat pembinaan narapidana agar memperbaiki diri sebelum kembali kelingkungan masyarakat. Undang-undang no 12 tahun 1995 pasal 2 menyebutkan bahwa "sistem pemasyarakatan diselenggarakan dalam rangka membentuk narapidana agar menjadi manusia seutuhnya, menyadari kesalahan, memperbaiki diri dan tidak mengulangi tindak pidana sehingga dapat diterima kembali oleh lingkungan masyarakat, dapat aktif berperan dalam pembangunan dan dapat hidup secara wajar sebagai warga yang baik dan bertanggung jawab". Narapidana yang dibina didalam lapas dilakukan pembinaan dengan menggunakan sistem, tatanan mengenai arah dan batasserta tatacara pembinaan sebagai mana diatur dalam pasal 1 ayat (2) Undang-undang no 12 tahun 1995 "sistem pemasyarakatan adalah suatu tatanan mengenai arah dan batas serta cara pembinaan Warga Binaan pemasyarakatan berdasarkan pancasila yang dilaksanakan secara terpadu Antara Pembina, yang di bina, dan masyarakat untuk meningkatkan kualitas Warga Binaan Pemasyarakatan agar menyadari kesalahan, memperbaiki diri, dantidak mengulangi tindak pidana sehingga dapat diterima kembali di lingkungan masyarakat". Tujuan pemayasayakatan aalah agar narapidana kembali menjadi manusia seutuhnya yang pulih hubungan Hidup, kehidupan dan penghidupannya. Hidup adalah hubungan manusia dengan Tuhannya, kehidupan adalah hubungan manusia dengan manusia lainnya dan penghidupan adalah hubungan antara manusia dengan lingkungannya. Oleh sebab itu narapidana dilakukan pembinaan untuk berupa pembinaan kemandirian dan kepribadian untuk meningkatkan kualitas diri narapidana.

Untuk dapat menjalankan fungsi pembinaan secara efektif maka sangat diperlukan kondisi lembaga yang kondusif sehingga mendukung pelaksaaan pembinaan. Namun dalam pelaksanaan pidana penjara berbagai permasalahan yang terjadi terutama terkait ganguan kamtib seperti kericuhan, penyeludupan, pembakaran hingga pellarian narapidana dan overcapasitas.

Pelarian narapidana merupakan masalah yang dihadapi oleh pemasyaraktan dalam melakukan pembinaan terhadap narapidana. Narapidana yang melarikan diri merupakan salah satu gangguan keamanan dan ketertibatan didalam Lapas atau Rutan. Tak hanya itu, pelarian juga menimbulkan keresahan pada masyarakat dengan keberadaan narapidana yang kabur di lingkungnan mereka. Masyarakat merasa keamanannya terancam ditambah dengan mudahnya berita kaburnya narapidana dari penjara tersebar melalui media.

Beberapa kasus pelarian narapidana dari Lembaga pemasyarakatan Indonesia saperti pelarian narapidana dari Rumah Tahanan Negara klas II B Wates, dengan masuk kedalam gorong-gorong kamar mandi kemudian merusak jeruji besi. Setelah itu narapidana melewati pos yang tidak dijaga oleh petugas kemudian lalu melompati pagar yang berkawat duri ${ }^{1}$. (fakta 5 narapidana rutan wates melarikan diri, 2019). Kasus lainnya adalah pelarian oleh narapidana yang menjadi tamping pada Lapas Klas II A Sidoarjo ketika membuang sampah dan tidak diawasi petugas (tamping kabur dari lapas klas II A Sidoarjo, 2019).

Narapidana melakukan pelarian dari dalam lapas atau rutan dipengaruhi oleh banyak faktor seperti, tekanan mental selama didalam lembaga, kekerasan fisik, terlibat hutang hingga tidak mau menjalani kewajiban pidana. Berbagai modus digunakan oleh narapidana untuk membebaskan diri dari lapas atau rutan seperti melakukan perusakan terhadap sarana lapas, memanfaatkan kelengahan petugas atau memanfaatakn kondisi yang tidak kondusif. Kasus kaburnya narapidana bukan lagi menjadi masalah yang baru, tetapi sudah terjadi sejak sistem kepenjaraan hingga sekarang dan selalu ramai dalam pemberitaan media. Begitu pula kasus pelarian empat orang narapidana dari rutan klas II B Sungai Penuh sehingga penulis tertarik untuk melakukan pembahasan terkait faktor penyebab kaburnya narapidana dan melakukan upaya pencegahan terjadinya kembali kasus kaburnya narapidana khusunya di Rutan kla II B

1Candra Setia Budi,"fakta 5 napi rutan Wates kabur, 3 berhasil ditangkap, 2 masih kabur", https://yogyakarta.kompas.com/read/2019/10/28/17075291/fakta-5-napi-rutan-wates-kabur-3berhasil-ditangkap-2-masih-kabur?page=all, diakses pada 30 oktober 2020, 22:21 
Sungai Penuh Penelitian ini juga dimaksudkan untuk menjawab pertanyaan apakah faktor yang menyebabkan narapidana melarikan diri dari rutan II B Sungai Penuh dan bagaimana mencegah terjadinya pelarian dari Rutan II B Sungai Penuh.

Ronald V. Clarke mengembangkan teori situational crime prevention sebagai strategi pencegahan kejahatan yang ditunjukkan untuk suatu jenis kejahatan yang spesifik dan bertujuan untuk mengubah situasi dan kondisi yang pada awalnya menguntungkan pelaku kejahatan. Dalam hal strategi pencegahan kejahatan ${ }^{2}$, teknik pencegahan kejahatan yang meliputi Situational crime prevention pada dasarnya mencari cara yang sederhana untuk mengurangi kejahatan melalui tiga langakah umum:

1. Membuat desain keamanan

2. Mengorganisasi prosedur yang efektif, yaitu melalui serangkaian upaya perencanaan dan penggunaan prinsip-prinsip manajemen,

3. Mengembangkan produk yang aman, yaitu menciptakan produk yang sulit dicuri atau disalahgunakan ${ }^{3}$

Pencegahan kejahatan berbeda dengan pengendalian kejahatan. Pengendalian kejahatan berkaitan dengan pemeliharaan jumlah prilaku yang berkaitan dengan kejahatan tersebut.Sedangkan pencegahan kejahatan menurut Steven P. Lab merupakan sebuah tindakan yang dilakukan untuk menghilangkan kejahatan atau mencegah kejahatan tersebut berkembang jauh (Lab,2013:31).

Penelitian yang dilakukan oleh Riky Novarizal, M.Krim \& Herman, M.Si dengan judul Pengamanan Lembaga Pemasyarakatan Terhadap Kemungkinan Terjadinya pelarian (Studi Kasus Lapas Kelas li A Pekanbaru). Penelitian ini dilakukan pada tahun 2019 menyimpulkan bahwa strategi yang dilakukan oleh Lapas Klas II A Pekan Baru dalam mencegah larinya narapidana adalah dengan melengkapi sarana prasarana pengamanan, melakukan pengecekan barang bawaan pengunjung secara teliti, melakukan penambahan jumlah petugas pengamanan karena jumlah petugas belum sebanding dengan jumlah narapidana dan meningkatkan pemahaman petugas khusunya petugas pengamanan agar mampu melaksanakan tugas sebagaimana mestinya.

Penelitian yang dilakukan oleh Muhammad Fatahillah Akbar dengan judul Politik Hukum Pidana Terhadap Perbuatan Narapidana Melarikan Diri Dari Lembaga Pemasyarakatan Di Indonesia yang dilakukan pada tahun 2019 menyimpulkan bahwa harus dilakukan perbaikan kekosongan hukum dimana kasus pelarian hanya digolongkan sebagai hukuman disiplin bukan sebagai hukuman pidana, sementara hukuman disiplin yang diberikan juga tidak berat. Kasus pelarian narapidana memenuhi parameter kriminalisasi sehingga dapat dilakukan amandemen Undang-undang No 12 Tahun 1995 tentang Pemasyarakatan dengan memasukan pelarian narapidana sebagai sebuah perbuatan pidana.

\section{METODE}

Pendekatan penelitian yang digunakan dalam penelitian ini adalah pendekatan kualitatif. Menurut Iskandar (2008:17) pendekatan kualitatif merupakan pendekatan penelitian yang memerlukan pemahaman yang permasalahan untuk mendapat data-data kemudian menganalisis dan mendapat kesimpulan penelitian dalam situasi dan kondisi tertentu. Metode penelitian adalah Studi, Surachrnad menjelaskan metodes studi kasus sebagai pendekatan penelitian yang berfokus dan memperhatikan dengan seksama suatu kasus dengan intensif dan rinci, dengan penggalian informasi dan analisa secara mendalam,Surachrnad (1982). Data yang di dapatkan disajiakan dalam bentuk diagram fishbone, diagram Fishbone atau digaram tulang ikan juga dikenal dengan nama Cause and Efect Diagram merupakan sebuah metode yang diperkenalkan oleh Prof. Kaoru Ishikawa dari Universitas Tokyo di tahun 1953. Diagram fishbone ${ }^{4}$. Diagram ini

\footnotetext{
${ }^{2}$ Kemal, N. N., A. Karim, Asmawati, Seniwati, Analisis Kandungan $\beta$-Karoten dan Vitamin C dari Berbagai Varietas Ubi Jalar(jakarta: Ipomea batatas),hlm1-8.

${ }^{3}$ Clarke, M dan Stewart, J. 1997, Community Governance, Community Leadership and the new local government, York Publishing Services, York, hal-51

4 Budi Kho, "Pengertian Cause and Effect diagram (Fishbone diagram) cara membuatnya", https: / /ilmumanajemenindustri.com/pengertian-cause-effect-diagram-fishbone-diagram-cara-membuatce/, diakses pada 02 November 2020, 21:54
} 
dipergunakan untuk :

1. Meng-identifikasikan akar penyebab dari suatu permasalahan

2. Mendapatkan ide-ide yang dapat memberikan solusi untuk pemecahaan suatu masalah

3. Membantu dalam pencarian dan penyelidikan fakta lebih lanjut

Penerapan diagram Fishbone dalam Organisasi akan membantu pimpinan melakukan analisa dan mencari akar penyebab masalah organisasi yang terjadi terutama organisasiorganisasi pemerintahan yang memiliki stigma buruk pada masyarakat karena pelayanan yang diberikan dimana ada banyak variabel yang memepengaruhi buruknya pelayanan oleh organisasi pemerintahan yang berpotensi akan menyebabkan rendahnya kepercayaan masyarakat. Dengan mengidentifikasi masalah yang terjadi serta penyebab-penyebabnya maka akan memudahkan dalam menentukan langkah perbaikan kebijakan organisasi untuk menigkatkan layanan publik dan kepercayaan masyarakat. Hal ini juga berlaku pada pemasyarakatan baik lapas maupun Rutan. Pelarian narapidana menjadi masalah gangguan kamtib yang harus mampu di atasi dan ditangani dengan baik. Pemaanfaatan diagram Fisbone (diagram tulang ikan) digunakan untuk mengidentifikasi penyebab kaburnya narapidana hingga akar-akar permasalahan kaburnya narapidana dari Lapas atau rutan. Setelah mengethaui penyebab dan akar permasalahan kaburnya narpidana dari Lapas atau Rutan maka dapat dilakukan evaluasi untuk perbaikan sistem kedepannya dan dapat diterapkan kepada UPT pemasyarakatan lainnya agar tidak lagi terulang kasus Pelarian narapidana.

\section{HASIL DAN PEMBAHASAN}

Berdasarkan hasil observasi dan studi kasus yang terhadap kasus pelarian narapidana di Rutan II B Sungai Penuh dengan mempelajari dokumen-dokumen terkait, melakukan observasi lingkungan dan bangunan lapas serta menggali informasi dari informan baik petugas mapun narapidana yang dapat memberikan data terkait kasus pelarian ini.

Penggalian data kepada informan dilakukan dengan teknik wawancara, dari informan petugas dan narapidana serta observsi maka didapatkan ada empat faktor yang menyebabkan pelarian narapidana di Rutan klas II B Sungai Penuh yaitu :

1. Manusia

2. Metode

3. Mesin, dan

4. lingkungan

faktor penyebab kaburnya narapidana digambarkan dalam diagram fisbhone berikut:

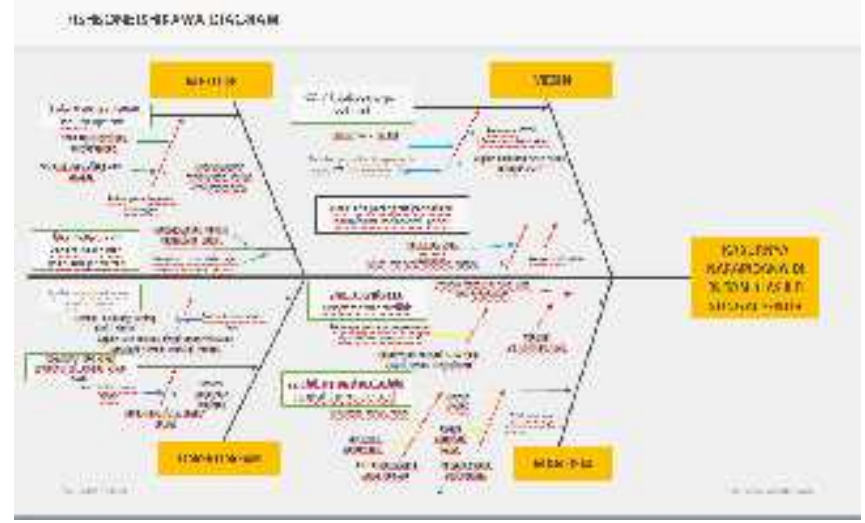

Gambar.1 diagram fishbone kaburnya narapidana rutan II B Sungai Penuh 


\section{Faktor Metode}

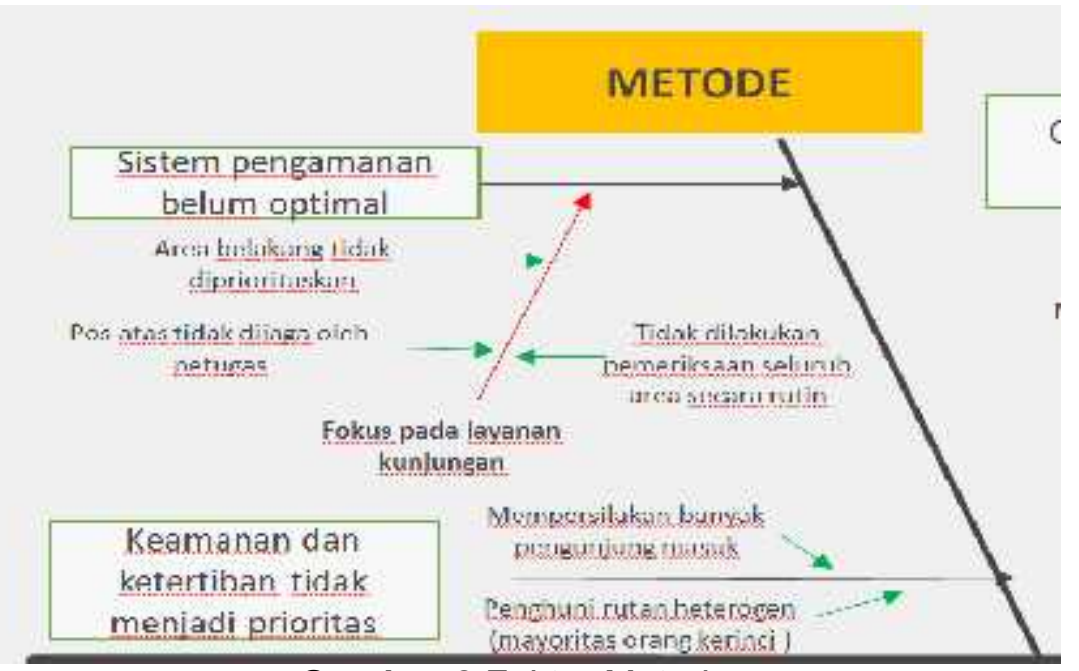

Gambar.2 Faktor Metode

Metode dalam hal ini adalah prosedur yang diterapkan oleh Rutan klas II B Sungai Penuh dalam penyelenggaraan kemanan dan ketertiban. Menurut Wiradi Metode adalah seperangkat langkah dari apa yang harus dikerjakan secara tersusun dan sistematis ${ }^{5}$. Dalam kasus ini metode yang menjadi faktor penyebab kaburnya narapidana dari rutan terbagi menjadi dua yaitu karena sistem pengaman yang belum optimal dan keamanan dan ketertiban tidak menjadi prioritas utama. Sistem pengamanan yang belum optimal ditujukan dengan hal hal berikut :

1. keamanan area belakang rutan tidak diprioritaskan

2. pos atas tidak dijaga oleh petugas

3. tidak dilakukan pemeriksaan seluruh area rutan secara rutan dan detail

4. fokus UPT adalah pada layanan kujungan karena momen Idul Fitri kemanan dan ketertiban tidak menjadi prioritas dirunjukan dengan faktor berikut:

1. mempersilakan banyak pengujung yang masuk karena momen idul fitri

2. penghuni yang heterogen (mayoritas adalah orang kerinci) sehingga muncul rasa terlalu percaya oleh petugas.

Metode standar penyelengaraan pengamanan rutan dan lapas sebagaimana telah disusun pada modul Pengaman pada Lapas Rutan yang disusun oleh Pusat pengembangan teknis dan kepemimpinan BPSDM HUKUM dan HAM tahun 2017. Dalam modul ini dijelaskan secara rinci pelaksanaan terkait pelaksanaan pengamanan. Pengamanan adalah segala bentuk kegiatan dalam rangka memberikan perlindungan, pencegahan, dan penindakan terhadap setiap ancaman dan gangguan dari dalam dan luar Lapas dan Rutan'. Pelaksanaan pengamanan meliputi penggeledahan, penjagaan, pengaman dan pengawalan. Penjagaan yang harus dilakukan berdasarkan modul ini meliputi sektor-sektor berikut :

1. penjagaan pintu gerbang halaman depan

2. penjagaan pos atas

3. penjagaan lingkungan blok

4. penjagaan blok

5. penjagaan ruangan kunjungan

\footnotetext{
5Mas Min," 17 Pengertian dan definisi metode menurut para ahli terlengkap" (https://www.pelajaran.co.id/2016/16/pengertian-dan-definisi-metode-menurut-para-ahliterlengkap.html, diakses pada 03 November 2020, 22:06

6 Samsul Hidayat, Bc.IP.,SH,Modul Pengamanan Pada Lapas dan Rutan(Jakarta: Pusat Pengembangan Teknis dan Kepemimpinan Badan Pengembangan Sumber Daya Manusia Hukum dan HAM, 2017) hlm10.
} 
petugas pengajagaan harus mampu melakukan pengawasan dan pengamanan pada seluruh area lingkungan lapas. Tugas tambahan berupa pengamanan pada pelayanan kunjungan keluarga khususnya di momen Idul Fitri tidak boleh menyebabkan kelengahan petugas pada sektor yang utama yang harus diamankan. Tambahan petugas staf dalam membantu pelaksanaan pengamanan bisa di optimalakan untuk menurunkan resiko gangguan kamtib yang kemungkinan muncul. Penjagaan pada pos atas merupakan bagian terpenting dari pengamanan untuk melakukan kontrol disekitar lingkungna Rutan. Kasus pelarian yang terjadi di Rutan klas II B Sungai Penuh dilakukan dengan memanfaatkan situasi penjagaan pos atas yang tidak pernah diisi.

Pelaskanaan kontrol sebagai mana diatur dalam halaman 35 pelaksanaan kontrol meliputi hal-hal berikut :

1. Kontrol dilakukan secara rutin oleh Kepala dan Wakil Kepala Regu Pengamanan.

2. Pelaksanaan kontrol dilengkapi dengan peralatan kontrol.

3. Kepala atau Wakil Regu Pengamanan sekurang-kurangnya melakukan kontrol setiap 1 (satu) jam sekali atau sesuai dengan situasi dan kondisi.

4. Kontrol dilakukan pada seluruh area rutan

Pelasksanaan kontrol merupakan tindakan pencegahan terutama upaya pelarian dengan melakukan penggalian lubang tembok rutan tentunya akan membutuhkan waktu yang cukup lama, dengan pelaksanaan kontro yang baik maka upaya pelarian akan lebih cepat terdeteksi.

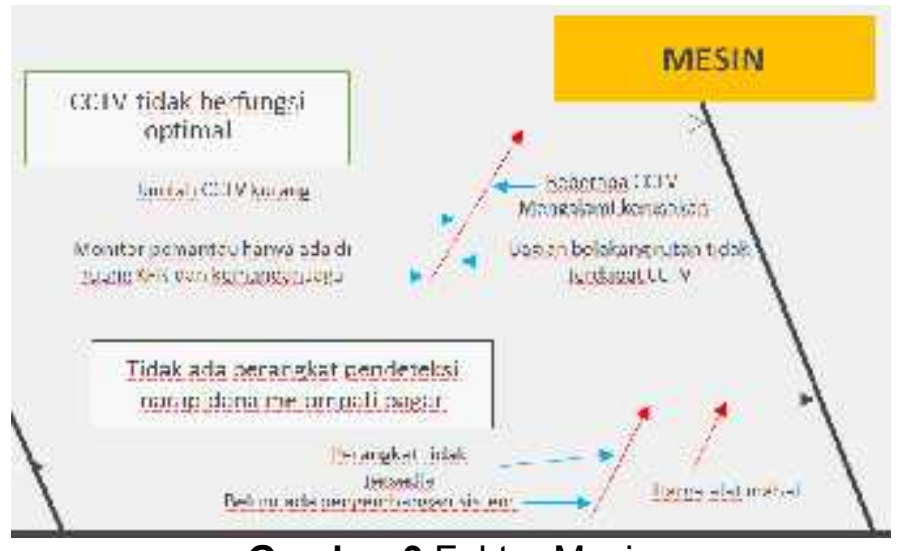

Gambar.3 Faktor Mesin

\section{Faktor Mesin}

Faktor mesin ini merupakan sarana yang mendukung pelaksanaan pengaman rutan berupa perangkat-perangkat yang memudahkan dan mengoptimalkan pengawasan petugas. Faktor mesin disebabkan oleh dua hal yaitu CCTV yang tidak berfungsi Optimal dan Tidak ada perangkat yang bisa mendeteksi jika naradana melompati tembok keliling.

CCTV yang tidak berfungsi Optimal disebabkan faktor-faktor berikut :

1. Jumlah CCTV yang belum mencukupi (kurang)

2. Monitor pemantau CCTV hanya tersedia pada ruangan Ka.KPR dan Komandan Jaga 
3. Beberapa titik CCTV mengalami kerusakan dan tidak berfungsi

4. Bagian belakang Rutan tidak terdapat CCTV

Tidak ada perangkat pendeteksi jika narapidana melompati pagar hal ini disebabkan :

1. Perangkat seperti ini belum tersedia dan sulit didapatakan

2. Belum ada pengembangan secara serius perangkat ini

3. Harga alat dan pengembagnannya mahal

Teknologi merupakan sarana yang bisa dimanfaatkan untuk meningkatkan kinerja manusia. Hal ini juga akan berlaku pada pelaksanaan pengamanan di Lapas dan Rutan. Menurut Merriam Webster, teknologi merupakan sebuah penerapan akan ilmu pengetahuan yang disebut juga sebuah aplikasi manusia ${ }^{7}$. Keterbatasan petugas pengamanan pada UPT pemasyarakatan dapat diturunkan resikonya dengan pengaplikasian berbagai teknologi penunjang pengamanan yang memudahkan pekerjaan petugas. Perlangkapan berupa CCTV tentunya akan sengat efektif karena monitor pemantu juga tersedia pada ruang KA.KPR dan Komandan Jaga. Setiap pergerakan yang terjadi di dalam lingkungan rutan mudah dipantau. Teknologi lainnya berupa sensor untuk mendeteksi jika narapidana melompati tagar keliling rutan juga harus segera dikembangkan untuk meminimalisir kasus kaburnya narapidana.

Pada pelaksanaannya di Rutan Klas II B Sungai Penuh, berdasarkan observasi dan wawancara kepada petugas regu penjagaan ditemukan bahwa perlengkapan CCTV yang tersedia dan aktiv di rutan lebih terfokus pada pengawasan kegiatan di sekeliling kantor, area belakang Rutan yang memliki steril area seluas 2 hingga 3 meter luput dari fokus pemasangan CCTV. Sehingga kejadian pelarian narapidana melalui tembok belakang tidak mampu dimonitor oleh petugas pengamanan. Pemasangan CCTV diarea belakang Rutan juga sebagai upaya untuk meminimalisir resiko karena pos atas yang tidak diisi, hal ini terjadi karena kurangnya jumlah petugas pengamanan sehingga tidak cukup untuk mengisi pos atas dan fasilitas pos yang belum memadai.

\footnotetext{
7 "Merriam-Webster Dictionary". Encyclopædia Britannica Online. 2015. Diakses tanggal 07 November 2020, 21.42
} 
Faktor Manusia

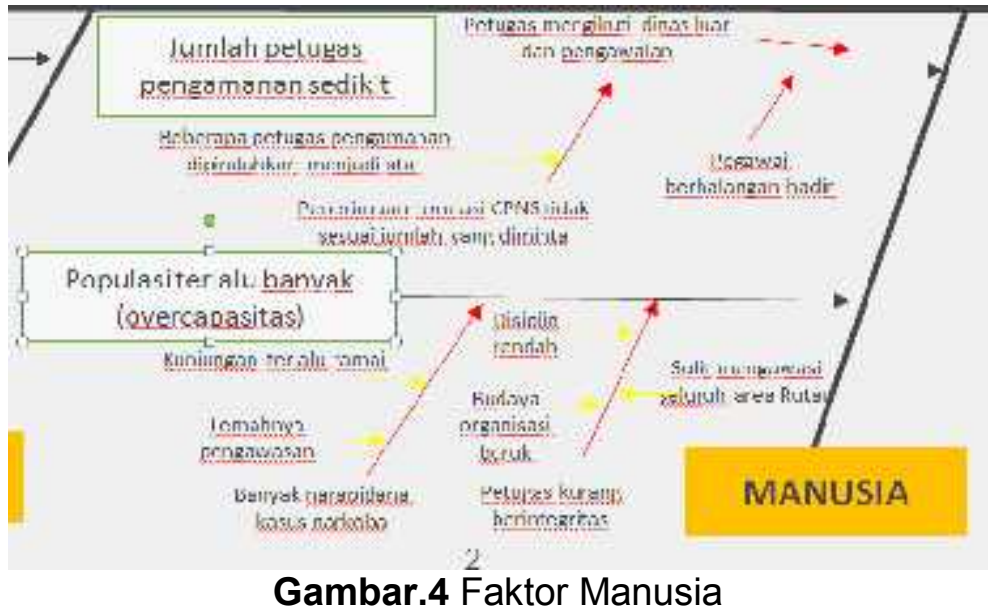

Faktor SDM merupakan isu yang sudah lama menjadi kendala dalam pelaksanaan tugas Pemasyaraktan, keterbatasn SDM baik secara kualitas maupun kuantitas seing kali menyebabkan beberapa masalah yang dapat menghambat peranan pemasyaraktan. Faktor sumber daya manusia yang menyebabkan pelarian narapidana rutan II B Sungai Penuh terbagi menjadi dua yaitu jumlah petugas pengaman yang seidkit dan populasi yang terlalu banyak (OVERCAPASITAS)

Kurangnya jumlah petugas disebabkan oleh hal-hal berikut :

1. Beberapa petugas pengamanan dipindahkan menjadi staf pada Subsie. Pengelolaan dan Subsie Pelayanan Tahanan

2. Penerimaan Formasi CPNS tahun 2017 lebih sedikit dari jumlah yang diminta

3. Pegawai yang berhalangan hadir

4. Pegawai mengikuti dinas luar atau pengawalan sehingga mendapatkan jatah libur

Populasi yang terlalu banyak disebabkan oleh faktor berikut:

1. Kunjungan keluarga yang terlalu ramai pada saat idulfitri

2. Banyaknya narapidana kasus narkoba

3. Sulitnya pengawasan oleh petugas

4. Disiplin rendah

5. Budaya organisasi yang buruk

Jumlah petugas pengamanan yang bertugas di Rutan Klas II B Sungai Penuh adalah 16 orang. 16 orang petugas ini kemudian di bagi kedalam empat regu. Empat regu ini bertugas dalam tiga shift satu hari kerja, hal ini seperti diatur dalam Modul Pengamanan Pada Lapas dn Rutan : "Pelaksanaan Penjagaan dilakukan dengan pergantian petugas pengamanan antar waktu (shift) di bagi 3 (tiga) kali dalam 1 (satu) hari" ${ }^{8}$. Empat orang ini terdiri dari satu komandan jaga, dua orang petugas P2U dan satu petugas blok. Berdasarkan hasil wawancara kepada petugas bahwa sebelumnya sebelum dipindahkan menjadi staf karena kekurangan pegawai, jumlah satu regu jaga adalah lima orang dengan satu petugas menjaga pos atas.

${ }^{8}$ Samsul Hidayat, Bc.IP.,SH.op.cit.hlm 14 
Penerimaan layanan kunjungan dengan kapasitas yang lebih besar pada momen idul fitri menyebabkan petugas terfokus pada pengawasan pelaksanaan kunjungan dan lengah melakukan pengawasan area belakang. Dalam hal ini sangat diperlukan penigkatan kualitas petugas dengan pembekalan dasar-dasar intelijen untuk memaksimalkan kinerja pengamanan dengan kurangnya jumlah personil pengamanan. Hal ini sebagaimana di jelaskan dalam Modul Teknik Dan Strategi Penanganan Huru Hara Pendidikan Dan Pelatihan Teknis Pengamanan Lapas Dan Rutan oleh Pusat Pengembangan Teknis dan Kepemimpinan Badan Pengembangan Sumber Daya Manusia Hukum dan HAM, "Upaya yang dapat dilakukan untuk mencegah terjadinya gangguan keamanan dan ketertiban pada Lapas atau Rutan melalui berbagai cara, yaitu: pemeriksaan pintu masuk, penjagaan, pengawalan, penggeledahan, inpeksi, control, kegiatan Intelijen, pengendalian peralatan, pengawasan komunikasi, pengendalian lingkungan, penguncian, penempatan dalam rangka pengamanan, investigasi dan reka ulang dan tindakan lain sesuai dengan ketentuan peraturan perundang-undangan" 9 . Dengan peningkatan kompetensi Petugas teruma dengan pembekalan ilmu Inteligensi diharapakan petugas pemasyaraktan terutama regu penjagaan mampu mengumpulkan Informasi dan melakukan deteksi dini terhadap perkiraan kemungkinan terjadinya permsalahan gangguan kamtib. Terutama isu-isu terkait perkelahian, peredaran narkoba dan Hndphone, kericuhan antar kelompok dan upaya pelarian oleh narapidana.

Selain meningkatkan kompetensi petugas, faktor manusia yang juga mempengaruhi adalah banyaknya tamu kunjungan narapidana terutama pada Momen hari Raya Idul Fitri. Kunjungan dalam jumlah besar ini cukup unuk mengalihkan perhatian petugas sehingga upaya penggalian tembok untuk melarikan diri lupt dari pengawasan petugas. Maka untuk itu dalam pelaksanaan kedepan, penerimaan layanan kunjungan dilakukan pembatasan, sesuai dengan ketersediaan petugas dan kemapuan pengawasan petugas sehingga resiko gangguan kamtib dapat diturunkan.

\footnotetext{
${ }^{9}$ Dony Setiawan,A.Md.IP,S.H.M.M, Teknik dan strategi penanganan Huru-Hara Pendidikan Dan Pelatihan Teknis Pengamanan Lapas dan rutan (Jakarta: Pusat Pengembangan Teknis dan Kepemimpinan Badan Pengembangan Sumber Daya Manusia Hukum dan HAM, 2017)hlm23
} 


\section{Faktor Lingkungan}

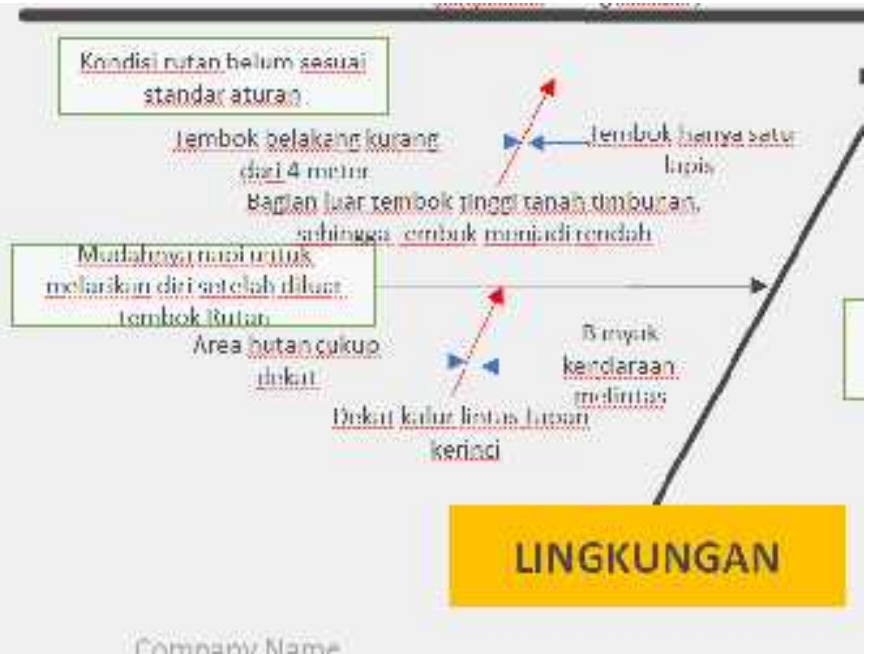

Gambar.5 Faktor Lingkungan

Faktor lingkungan rutan juga memberikan memberikan pengaruh yang besar terhadap pelaksanaan pengamanan Rutan. Lingkungan sekitar rutan yang memiliki memberikan peluang yang memudahakan narapidana untuk melarikan diri dari rutan. Hal ini dikarenakan dua faktor yaitu kondisi rutan yang belum sesuai standar aturan dan mudahnya narapidana melarikan diri setelah diluar tembok rutan.

Kondisi Rutan yang belum sesuai standar disebabkan faktor berikut :

1. Tembok keliling kurang dari 4 meter tingginya

2. Bagian sisi luar tembok keliling sudah tinggi tanah timbunan (hampir dua meter)

3. Tembok yang hanya satu lapis

Mudahnya narapidan melarikan diri setelah berada diluar tembok rutan terjadi karena faktor berikut :

1. Area hutan yang berada cukup dekat dari Rutan

2. Rutan dekat dengan jalur lintas Kerinci-Tapan

3. Banyakya kendaraan umum baik truk maupun travel yang melintas di depan rutan kearah Tapan

Kondisi pola bangunan Rutan Klas II B Sungai Penuh menjadi salah satu faktor yang memudahkan narapidana melakukan upaya pelarian. Hasil wawancara terhadap petugas yang menjadi Informan mengungkapkan bahwa "narapidana yang melarikan diri memanfaatkan saluran drynase yang berada diantara dapur dan kamar hunian, area ini sulit dipantau oleh petugas karena tidak terlihat dari pos jaga dan dihalangi dengan pakaian yang dijemur oleh narapidana. Setelah melakukan pembobolan tembok maka tidak ada lagi yang menghalangi empat orang narapidana itu melarikan diri karena tembok yang relatif mudah untuk di naiki dan kosongnya pos atas".

Berdasarkan observasi, Kondisi tembok memiliki tinggi sekitar empat meter jika dilihat dari sisi dalam Rutan, namun jika dilihat dari sisi luar tembok belakang, maka tinggi tembok hanya berkisar 2,5 hingga 3 meter, hal ini disebabkan tingginya timbunan tanah oleh bangunan rumah sakit swasta yang berada di belakang Rutan. Berikut gambar yang menunjukan kondisi tembok Rutan yang di ambil dari pos atas 


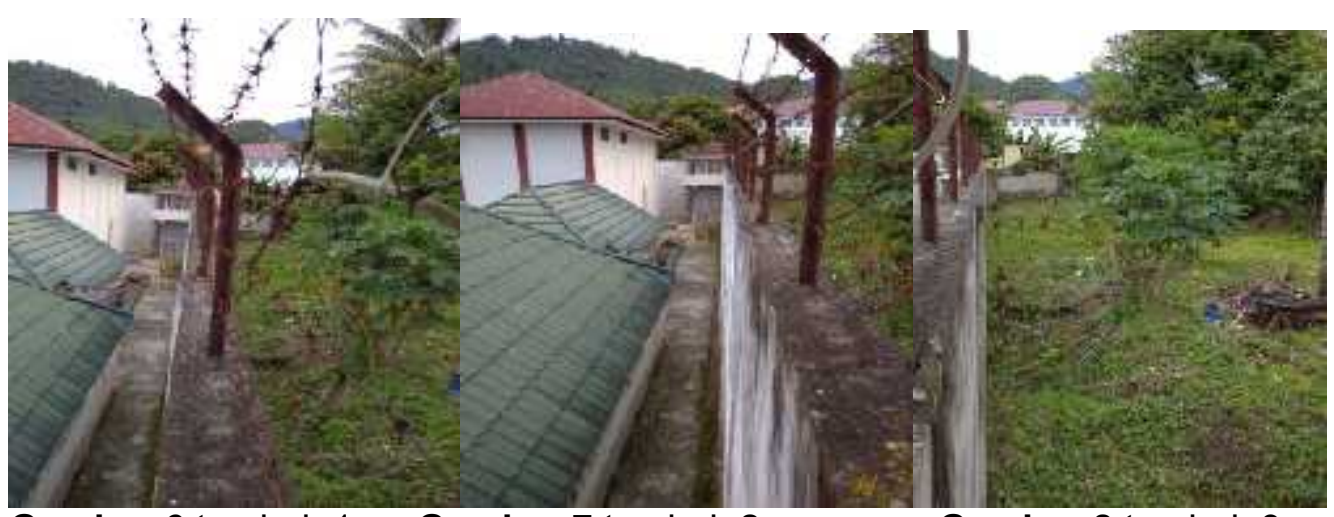

Gambar.6 tembok.1 Gambar.7 tembok.2

Gambar.8 tembok.3

Berdasarakan gambar-gambar dan hasil observasi terlihat jelas perbedaan tinggi permukaan antara sisi luar tembok rutan dan sisi bagian dalam, selisih perbedaan permukaan lebih dari satu meter.

Berdasarkan Keputusan Menteri Kehakiman Dan Hak Asasi Manusia Republik Indonesia Nomor : M.01.PI.01.01 Tahun 2003 Tentang Pola Bangunan Unit Pelaksana Teknis Pemasyarakatan, standar pengamanan rutan berupa tembok dan pagar keliling dijelaskan dalam pasal 6 ayat (1) dan (2) berikut :

1) Pagar Rutan terdiri dari :

a. pagar keliling; dan

b. pagar pembatas areal dalam Rutan.

c. Pagar keliling terdiri dari :

2) pagar pembatas sisi luar;

a. tembok keliling; dan

b. Ipagar keliling dalam ${ }^{10}$.

Rutan Klas II B Sungai Penuh belum dilengkapi dengan pagar pembatas sisi luar, sehingga hanya terdiri dari satu lapis tembok keliling dengan tinggi empat meter ditambah satu meter kawat baja berduri. Standar tembok keliling yang diatur dalam Keputusan Menteri Kehakiman Dan Hak Asasi Manusia Republik Indonesia Nomor : M.01.PI.01.01 Tahun 2003 Tentang Pola Bangunan Unit Pelaksana Teknis Pemasyarakatan adalah sebagai berikut :

Pasal 6 ayat (3) huruf b:

1) Bahan :

a) dinding beton bertulang K-400, bertulangan ganda $16 \mathrm{~mm}$, jarak $12 \mathrm{~cm}$, tebal bagian atas $20 \mathrm{~cm}$, tebal bagian bawah $40 \mathrm{~cm}$, kemiringan dinding pada bagian dalam;

b) dibagian atas pagar dipasang gulungan $\varnothing 60 \mathrm{~cm}$ kawat baja berduri anti karat lengkap dengan rangkanya.

2) Tinggi : Tinggi dinding beton $6 \mathrm{~m}$ ditambah $1 \mathrm{~m}$ gulungan kawat baja berduri (terpasang).

3) Pondasi : Plat lajur beton bertulang dari beton mutu minimal K-300.

4) Pintu : Berfungsi sebagai Pintu Gerbang Utama.

\footnotetext{
${ }^{10}$ Indonesia, Keputusan Menteri Kehakiman Dan Hak Asasi Manusia Republik Indonesia Tentang Pola Bangunan Unit Pelaksana Teknis Pemasyarakatan, Kepmenkumham No. M.01.P1.01.01 Tahun 2003
} 
5) Jarak : Jarak antara Tembok Keliling dengan Pagar Pembatas Sisi Luar sekurang-kurangnya $5 \mathrm{~m}$.

6) Prototype tembok keliling tersebut pada LAMPIRAN VI. 


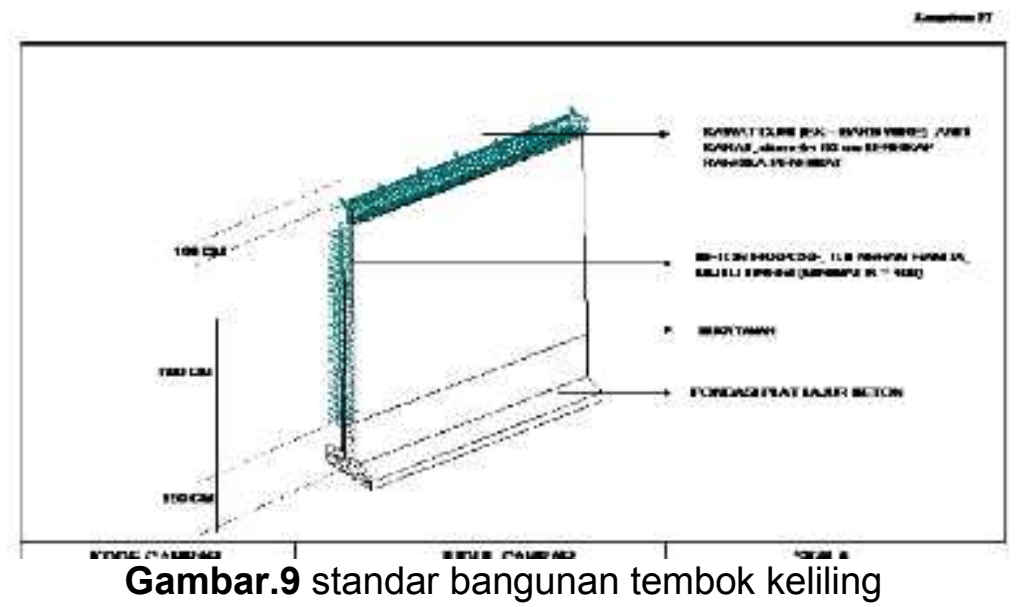

Berdasarkan aturan tersebut maka perlu dilakukan perbaikan tembok agar sesuai dengan standar yang telah di tetapkan sehingga fungsi tembok menjadi optimal meski terkendala untuk pembuatan pagar pembatas sisi luar karena terbatasnya lahan, bangunan Rutan sudah di bangunan bangunan lain seperti KODIM di sisi timur, Rumah sakit swasta disisi utara dan Kampus STIA/STIE disisi barat hingga tidak lagi memiliki lahan yang cukup untuk membangun pagar keliling luar.

\section{KESIMPULAN}

Faktor-faktor yang menyebabkan kaburnya narapidana dari Rutan Klas II B Subngai Penuh terdiri dari empat faktor :

1. Faktor metode karena sistem pengaman yang belum optimal dan keamanan dan ketertiban tidak menjadi prioritas utama.

2. Faktor mesin karena CCTV yang tidak berfungsi Optimal dan Tidak ada perangkat yang bisa mendeteksi jika naradana melompati tembok keliling.

3. Faktor manusia karena jumlah petugas pengaman yang seidkit dan populasi yang terlalu banyak (OVERCAPASITAS)

4. Faktor lingkungan karena kondisi rutan yang belum sesuai standar aturan dan mudahnya narapidana melarikan diri setelah diluar tembok rutan.

\section{SIMPULAN DAN SARAN}

Dalam rangka pencegahan terjadinya gangguan kamtib maka petugas Rutan sungai penuh harus mampu meningkatkan kewaspadaan terhadap kemungkinan terjadinya gangguan kamtib. Keadaan yang aman dan tertib tidak boleh membuat petugas selalu merasa aman hingga menurunkan kewaspadaan. Peningkatan sarana penunjang keamanan seperti CCTV dan kecapkapan petugas dalam pemantauan akan menjadi alternatif solusi masalah kurangnya tenaga pengamanan. Tembok keliling sangat perlu dilakukan pembenahan sesuai aturan yang berlaku untuk meminimalisir resiko gangguan kamtib mengingat tidak mungkinya membangun pagar pembatas luar.

\section{DAFTAR PUSTAKA}

Undang-Undang Republik Indonesia Nomor 12 Tahun 1995 tentang pemasyaraktan.

Keputusan Menteri Kehakiman Dan Hak Asasi Manusia Republik Indonesia Nomor : M.01.PI.01.01 Tahun 2003 Tentang Pola Bangunan Unit Pelaksana Teknis Pemasyarakatan 
Candra Setia Budi,'fakta 5 napi rutan Wates kabur, 3 berhasil ditangkap, 2 masih kabur' (2019) 1(1) EJLT <https://yogyakarta.kompas.com/read/2019/10/28/17075291/fakta-5-napi-rutanwates-kabur-3-berhasil-ditangkap-2-masih-kabur?page=all> diakses 30 oktober 2020.

Iskandar. 2008. Metodologi Penelitian Pendidikan dan Sosial (Kuantitatif dan Kualitatif). Jakarta: GP Press.

Mas Min,"17 Pengertian dan definisi metode menurut para ahli terlengkap" (2016) (https://www.pelajaran.co.id/2016/16/pengertian-dan-definisi-metode-menurut-para-ahliterlengkap.html, diakses 03 November 2020

Samsul Hidayat, Bc.IP.,SH,Modul Pengamanan Pada Lapas dan Rutan ( Pusat Pengembangan Teknis dan Kepemimpinan Badan Pengembangan Sumber Daya Manusia Hukum dan HAM, 2017) 10

Merriam-Webster Dictionary".Encyclopædia Britannica Online. 2015. Diakses tanggal 07 November 2020

Dony Setiawan ,A.Md.IP,S.H.M.M, Teknik dan strategi penanganan Huru-Hara Pendidikan Dan Pelatihan Teknis Pengamanan Lapas dan rutan (Pusat Pengembangan Teknis dan Kepemimpinan Badan Pengembangan Sumber Daya Manusia Hukum dan HAM, 2017)23.

Kemal, N. N., A. Karim, Asmawati, Seniwati.2013. Analisis Kandungan $\beta$-Karoten dan Vitamin C dari Berbagai Varietas Ubi Jalar (Ipomea batatas). Indonesia Chemica Acta, 1-8

Clarke, M dan Stewart, J. 1998, Community Governance, Community Leadership and the new local government, York Publishing Services, York.

Muhammad Fatahillah Akbar, POLITIK HUKUM PIDANA TERHADAP PERBUATAN NARAPIDANA MELARIKAN DIRI DARI LEMBAGA PEMASYARAKATAN DI INDONESIA Jurnal Hukum \& Pembangunan Vol. 50 No. 1 (2020): 20-34

Riky Novarizal, M.Krim \& Herman, M.Si PENGAMANAN LEMBAGA PEMASYARAKATAN TERHADAP KEMUNGKINAN TERJADINYA PELARIAN (Studi Kasus Lapas Kelas II A Pekanbaru), SISI LAIN REALITA. Vol.4,No.1 (2019): 90-102 